\title{
CULTURA ESCOLAR, AUTORIDADE, HIERARQUIA E PARTICIPAÇÃO: ALGUNS ELEMENTOS PARA REFLEXÃO
}

\author{
JOYCE MARY ADAM DE PAULAESILVA \\ Instituto de Biociências da Universidade Estadual Paulista - Rio Claro
}

\section{RESUMO}

Este artigo apresenta uma reflexão a respeito de algumas concepções teóricas de autoridade e hierarquia, e de como essas concepções se constituem em elementos da cultura escolar que é construída na interação cotidiana, definindo formas diferenciadas de participação nas escolas. Parte do pressuposto de que a escola, como organização burocrática, tem em sua estrutura um corpo de princípios e valores dados pelo sistema educacional, por meio de leis, decretos e papéis formalmente estabelecidos, e um outro corpo de princípios e valores construídos e reelaborados no seu interior, pelos participantes do processo educacional, formando a cultura escolar. Assim, o grau de participação nas escolas se definiria em razão das concepções que seriam compartilhadas e construídas nesse processo de constituição da cultura escolar.

AUTORIDADE - ESCOLAS - ADMINISTRAÇÃO ESCOLAR - VIDA ESCOLAR

\begin{abstract}
THE CULTURE OFSCHOOL, AUTHORITY, HIERARCHY AND PARTICIPATION: SOMEELEMENTS FOR REFLECTION. This article presents a reflection on some theoretical concepts of authority and hierarchy and how these concepts become elements of the school culture constructed in daily interactions, defining differentiated forms of school participation. It starts with the assumption that the school as a bureaucratic organization has a body of principles and values in its structure given by the educational system, through laws, decrees and formally established roles, and another body of principles and values constructed and re-elaborated on the inside by the participants in the educational process, forming a school culture. Thus the degree of participation in school is defined in function of the concepts that will be shared and constructed in the process of constituting the school culture.
\end{abstract}




\section{INTRODUÇÃO}

Autoridade e hierarquia são questões sempre presentes nas discussões e conflitos cotidianos da organização escolar.

O senso comum que acompanha tais conceitos não permite, muitas vezes, uma análise mais aprofundada do real significado e de como esses conceitos são construídos pelos que estão envolvidos no processo educacional.

A escola, como organização burocrática, tem em sua estrutura um corpo de princípios e valores dados pelo sistema educacional, por meio de leis, decretos e papéis formalmente estabelecidos, e um outro corpo de princípios e valores construídos e reelaborados no seu interior, pelos participantes do processo educacional. Esse corpo de princípios e valores é constituído na cultura da organização escolar e direciona grande parte das interações presentes nessa cultura.

Os conceitos de autoridade e hierarquia adotados no interior das escolas definem uma cultura de interação entre os seus participantes e são peculiares a cada organização, aspecto que será discutido neste artigo.

A reflexão sobre a cultura organizacional aplicada ao âmbito escolar derivou dos estudos a respeito da cultura empresarial, que se impôs na literatura de administração em geral há aproximadamente dez anos.

A importância desse tipo de abordagem foi destacada por Nóvoa ( 1995), ao afirmar que a utilização dos modelos de análise que introduzem alguns conceitos políticos e simbólicos, como poder, disputa ideológica, conflito, interesses, controle, regulação etc., permitem uma compreensão mais apurada da construção das estruturas da organização escolar.

Assim, este artigo pretende trazer uma reflexão a respeito de diferentes conceitos de autoridade e hierarquia, e de como a cultura escolar que é construída com base na interação cotidiana, direciona as escolas para diferentes formas de participação.

\section{OSENTIDO DA CULTURA ESCOLAR}

Previamente à reflexão sobre a cultura escolar, cabe uma referência às concepções do termo cultura, conforme literatura sobre o tema.

Em estudo realizado por Motta (1996), a respeito da relação entre a cultura nacional e a cultura organizacional, é destacado o conceito de cultura adotado pela antropologia contemporânea, principalmente o desenvolvido por Lévi-Strauss e Geertz.

Para Lévi-Strauss (1958), todas as culturas constituem-se em linguagem e códigos. A cultura teria a função de prover os grupos ou nações de um referencial que permitiria ao homem dar sentido ao mundo e às suas ações. 
A cultura, no entanto, segundo Geertz (1973), não é uma qualidade ou um poder determinante do comportamento individual, mas um sistema de relações e significados que permite uma descrição inteligível de comportamentos, valores, crenças e princípios dos diferentes grupos.

Nesse sentido, a cultura não atribuiria papéis e determinaria comportamentos dos quais os indivíduos não pudessem escapar, antes, eles estariam constantemente reinterpretando os significados, códigos e linguagens particulares de cada grupo ou nação.

No tocante especificamente às organizações, estas são parte de uma sociedade e de sua cultura, e constroem pressupostos básicos que são compartilhados (Motta, 1996). Esses pressupostos, no entanto, segundo o autor, passam por limitações de hierarquia e metas organizacionais.

A cultura organizacional, segundo Schein, seria:

Um conjunto de pressupostos básicos inventados, descobertos ou desenvolvidos por um dado grupo, ao aprender a lidar com problemas de adaptação externa e de integração interna que se revelou suficientemente adequado para ser considerado válido e, portanto para ser ensinado aos novos membros como o modo correcto de perceber, de pensar e de sentir os referidos problemas. (Apud Nóvoa, 1995, p. 29)

Segundo Thévenet ( 1991), a cultura é uma fonte de referências, exprimindo, ao mesmo tempo, a personalidade da organização e também a permanência e a coerência de um sistema de referências que ela constitui para si mesma, aparecendo como recurso e conseqüência do modo pelo qual a empresa trata seus problemas de ambiente e coesão interna.

Sendo um conteúdo, um conjunto de elementos que distingue uma organização da outra, a cultura pode ser localizada, descrita e escrita.

O conceito de cultura organizacional foi transportado para a área de educação na década de 70. A principal contribuição trazida por esse referencial de análise foi a possibilidade de uma análise das organizações escolares que vai além da racionalidade técnica e da racionalidade organizacional, constituindo-se em uma racionalidade político cultural (Nóvoa, 1995).

Erickson ( 1987 ) apresenta três definições de cultura que poderiam ser mais adequadas para estudar a organização escolar. A primeira delas analisa a cultura organizacional como um código genético, como um conjunto de pequenos pedaços que formam o todo de um grupo social.

Uma segunda concepção considera a cultura como uma estrutura conceitual construída a partir da visão da realidade de cada um dos membros do grupo, isto é, seria uma construção das visões compartilhadas por eles. Essa concepção busca traçar uma 
identidade entre os símbolos, valores e princípios compartilhados pelos diferentes membros do grupo: "este conceito enfatiza um firme padrão organizacional, coerência no sistema de significações e identidade na compreensão dos símbolos entre os diferentes membros do grupo social" (p. 13).

Uma terceira concepção considera a cultura como resultado do conflito no interior dos grupos sociais. A ênfase, portanto, seria no movimento constante dos valores, princípios, símbolos e regras resultantes das interações no interior da organização.

Ao contrário das duas primeiras concepções, que enfocam o estudo da cultura na tradição transmitida pela socialização, esta última concepção enfoca a cultura mais na perspectiva dos conflitos e negociações que se processam na criação da cultura compartilhada. O sentido da palavra "compartilhada" nesse caso é o de que padrões comportamentais, valores, princípios e regras são seguidos até que novas formas sejam reelaboradas, reinterpretadas e implementadas pelo grupo .

Nessa perspectiva, o interesse central não é o conhecimento da cultura em si, mas as relações entre a cultura estabelecida ou compartilhada e a situação concreta. Isto é, observar como essa cultura "compartilhada" gera comportamentos e reinterpreta as normas ditadas pelas políticas educacionais no interior das organizações.

Desse modo, as organizações escolares, por um processo constante de interação entre seus membros, estariam criando uma cultura orientadora das ações desses membros, sem, no entanto, constituir-se em um quadro estático. As diferentes visões da organização, os diferentes valores e crenças dos atores produzem uma dinâmica que se expressa na experiência concreta e nas realizações que se processam no interior da escola.

Giroux ressalta o caráter ideológico e de contestação que acompanha as diferentes formas de cultura que caracterizam as organizações escolares, fruto das diferentes visões e negociações que se processam: "as escolas são a incorporação histórica e estrutural de formas e cultura que são ideológicas no sentido de que elas têm o significado de realidades constantemente contestadas e experienciadas diferentemente pelos indivíduos e grupos" (apud Bates, 1987, p. 109, tradução nossa).

As organizações educacionais, como afirma Brunet (1995), apesar de estarem integradas em um contexto cultural mais amplo, relacionado à cultura nacional, cultura familiar etc., produzem uma cultura interna que as diferencia umas das outras.

Resumindo as diferentes concepções de cultura e sintetizando a diversidade de elementos que compõem a cultura organizacional e escolar, vemos que a cultura escolar seria resultado de um processo interativo, em que o universo dos símbolos e significados estariam constantemente sendo reinterpretados e a realidade construída. 
A compreensão da cultura da escola como um processo dinâmico e negociado entre os diferentes atores do processo pedagógico permite uma compreensão mais aprofundada da contribuição de tais atores na construção dos valores, crenças e princípios, assim como nas ações que se processam na realidade cotidiana.

Os estudos já realizados sobre culturas organizacionais das escolas apresentam diferentes metodologias, podendo abordar diversos de seus aspectos. Dentre eles, destaque-se o estudo realizado por Gomes ( 1993) que tem por objeto a identidade profissional dos professores, a cultura organizacional de duas escolas e sua influência no processo pedagógico escolar. A metodologia utilizada foi a do estudo das representações das práticas educativas e organizacionais, buscando explicitar os processos simbólicos presentes em ambas as escolas.

Nesse mesmo estudo, Gomes menciona outras abordagens metodológicas possíveis. Uma delas tem na análise da socialização prévia dos atores organizacionais um elemento fundamental para a definição da cultura escolar. Assim, a cultura nacional, a cultura de formação dos professores e de outros atores do processo educacional seriam elementos capazes de fornecer os princípios definidores da cultura escolar.

Outra abordagem, ainda, considera a diversidade da cultura intra-organizacional como ação de aprendizagem cultural e invenção e difusão de novos padrões culturais, tendo os processos conflitantes como elemento fundamental na construção da cultura.

Os enfoques apresentados relacionam-se com a reflexão proposta nesse artigo, na medida em que as concepções de autoridade, hierarquia e participação compartilhadas ou negociadas pelos diferentes atores do processo educacional são consideradas elementos que definem a cultura escolar e orientam as ações no cotidiano das escolas. Assim, a análise da cultura organizacional da escola, partindo dessas concepções, permite compreender as interações que se processam no seu interior e detecta as suas influências nos resultados educacionais.

\section{AUTORIDADE, HIERARQUIA E PARTICIPAÇÃO COMO COMPONENTES DA CULTURA ESCOLAR}

As concepções de autoridade, hierarquia e participação, compartilhadas pelos diferentes segmentos participantes das escolas, criam culturas diferenciadas em cada escola, em termos de organização e relações que diferenciam o processo educacional.

Em um artigo a respeito da construção da autoridade nas escolas, Elmore faz uma citação de Gerald Grant, cuja análise das diferentes concepções de autoridade nas escolas, através do tempo, é a seguinte: 
As escolas de ensino médio americanas de 1900 pareciam um abacate. Elas estavam centradas no poder dos adultos e as iniciativas estavam unificadas e virtualmente impregnadas em seu todo, sua camada média, representada pelos estudantes, era satisfatoriamente homogênea, e sua casca, representada pela política externa, era fina e claramente definida. A escola de ensino médio de 1950 era mais parecida com um melão, uma boa fruta da classe média com uma considerável expansão do corpo de estudantes. As políticas externas, tais como os exames para professores e guias curriculares cresceram em vários estados, mas no centro havia ainda uma considerável dependência das ações e iniciativas dos adultos. Se o staffera mais especializado, eles estavam ainda limitados por uma rede interna. As escolas médias de 1985 se parecem com uma melancia, com uma espessa camada de políticas federais e estaduais, uma forte expansão e diversificação do corpo de estudantes e um centro não definido claramente. Como sementes de melancia, os adultos especialistas estão dispersos e comandam, freqüentemente em conflito, partindo de diferentes lugares. (1987, p. 67, tradução nossa)

Nessa metáfora, Grant procura fazer uma reflexão sobre a organização da escola e o sentido da autoridade nesses diferentes momentos. A autoridade nas relações entre professores e alunos, professores e direção e entre a prática educativa cotidiana e as políticas educacionais é o objeto de reflexão na comparação feita. A dispersão e atomização dos profissionais da educação, bem como de suas práticas, seriam elementos dificultadores para que a escola tenha uma postura mais clara e negociada com respeito à autoridade que se estabelece em seu interior. Dessa forma, seria desejável uma clareza maior a respeito de princípios elementares que orientassem a ação dos participantes do processo educacional.

Nesse sentido, Elmore afirma que a estrutura racional-legal que caracteriza o sistema educacional hoje acarreta uma relação de autoridade legitimada antes pela desigualdade e hierarquia do que pela negociação.

A discussão do conceito de autoridade, assim como das bases de legitimação da autoridade, é fundamental na análise da problemática da escola e de sua cultura.

Segundo H. Arendt ( 1972, p. I29), a autoridade é comumente confundida com alguma forma de poder ou violência, quando, na verdade, "a autoridade exclui a utilização de meios externos de coerção; onde a força é usada, a autoridade em si fracassou". A autora afirma, ainda, que a autoridade é incompatível com a persuasão, na medida em que esta última pressupõe uma relação de igualdade. Conclui que a autoridade se encontra em contraposição tanto em relação à coerção física quanto à persuasão. $\bigcirc$ ponto em comum de quem manda e de quem obedece, numa situação de autoridade, é a hierarquia, cuja legitimidade ambos reconhecem. 
A legitimidade da autoridade é discutida por Weber (1944),com base no que chama de os três tipos puros de dominação legítima, que seriam o de caráter racional, o de caráter tradicional e o de caráter carismático. Como o objeto em questão é a organização escolar, a discussão se restringirá à dominação de caráter racional, na medida em que a escola é considerada como uma organização burocrática.

O poder, segundo Weber , seria a capacidade de provocar a aceitação de ordens, e a legitimidade seria a possibilidade de aceitação do exercício do poder; a autoridade, por sua vez, seria o poder considerado legítimo. A autoridade na organização burocrática provém das regras estabelecidas e dos cargos hierarquicamente organizados.

Dessa forma, a legitimidade da autoridade não seria emanada do indivíduo ou entre indivíduos em si, mas de cargos e normas pré-estabelecidos, pois como afirma Weber, a legitimação de caráter racional "se firma na crença da legitimidade das ordens estabelecidas e dos direitos de mando dos chamados pela organização para exercer a autoridade (autoridade legal)" (1944, p. 174 , tradução nossa).

Segundo a concepção apresentada por Weber e Arendt, para que haja autoridade é necessário um reconhecimento da sua legitimidade pelas partes envolvidas. A relação de hierarquia precisa ser considerada legítima para que se possa estabelecer a relação de autoridade. Simplificando as idéias discutidas, pode-se concluir que a legitimação da autoridade, segundo Arendt, se fundamenta essencialmente na tradição das práticas sociais reconhecidas pelos indivíduos e pelas instituições, ao passo que a legitimação da autoridade, segundo Weber, passaria essencialmente pelo cargo que os indivíduos ocupam nas organizações.

Somando-se a essas reflexões a concepção de que a hierarquia é um sistema de funções de subordinação e chefia (Thompson, 1967), funções que são aprendidas e culturalmente estabelecidas, variando tanto de uma cultura para outra quanto no tempo, pode-se concluir que o próprio conceito de hierarquia varia em decorrência de diferenças culturais, de época e de características organizacionais.

Para analisarmos a cultura das escolas, em termos da autoridade, hierarquia e participação, e as estruturas das relações que determinam essa cultura, será retomada a citação de Elmore:

A autoridade é uma relação recíproca, a aceitação da legitimidade baseada em uma reconhecida desigualdade. A aceitação pode ser baseada em um trato ou represália, tradição, respeito pelo conhecimento ou competência, ou regras formais. Nós podemos revogar ou consentir se nós percebemos que essa autoridade estiver em desacordo com o combinado. (1987, p.69, tradução nossa) 
Nessa citação, o autor chama a atenção para o fato de que a autoridade e a hierarquia são relações recíprocas e baseadas em elementos bem definidos, que podem ser ameaça, represália, tradição ou respeito pela competência e conhecimento, ou regra formal. Assim, a legitimidade existe ou deixa de existir na medida em que esses elementos sãos reconhecidos ou não, por aqueles que estão nessa relação.

As organizações escolares, por sua vez, também passam por um processo semeIhante de criação de uma cultura, que reflete os conceitos de autoridade e hierarquia e os elementos que os legitimam.

Os diferentes atores do processo educacional, pela sua interação cotidiana, criam as estruturas e tentam imprimir seus valores e crenças pela intervenção na realidade escolar.

A autoridade, a hierarquia e a participação permitidas, a partir daí, nas escolas, seja na relação professor-aluno, direção-professores, direção-pais, são legitimadas por diferentes elementos. A princípio, a autoridade do professor é conferida legalmente por sua formação; na relação com os alunos, pelo reconhecimento do saber do qual ele é detentor; na relação com a direção, pelo cargo que o primeiro ocupa.

Na realidade, no entanto, observa-se que o tecido das relações que se processam no interior das escolas apresenta embate e negociação constantes, pela legitimação ou pela supressão das autoridades aqui referidas.

O estudo de uma escola da periferia de São Paulo, Paro ( 1995) mostra o caráter hierárquico da distribuição de autoridade que prevalece nas escolas públicas, gerando uma relação de mando e obediência. Essa relação de mando e obediência encontra-se não somente nos regulamentos formais, mas também nas regras informais e na cultura que rege as relações e que legitima esse caráter hierárquico

O princípio da relação de desigualdade que está embutido no conceito de autoridade, referido por Hanna Arendt, é um dos elementos presentes nesse embate. Podese considerar que a desigualdade do aluno em relação ao professor encontra-se no reconhecimento do saber do qual o professor é detentor; a desigualdade do diretor em relação ao professor reside na função articuladora dos diferentes saberes que se encontram presentes na escola. Outros elementos poderiam caracterizar a desigualdade que legitima a relação de autoridade e hierarquia, como a legal-burocrática, ou o saber conferido por um diploma.

Dessa forma, as diferentes características culturais que as escolas apresentam estão em razão das interações e do embate entre as diferentes visões que se processam no cotidiano. Tais embates resultam em um padrão de comportamento organizacional que está em constante mutação e exprime as bases conceituais que o grupo compartilha. 


\section{ALGUMAS CONCLUSÕES}

Nos conceitos de autoridade apresentados, observou-se que a legitimação, ou a aceitação dessa autoridade pelos envolvidos, assume diferentes padrões. $O$ ponto comum entre quem manda e quem obedece, numa situação de autoridade, é a hierarquia cuja legitimidade ambos reconhecem, como já foi afirmado anteriormente.

No entanto, a origem do reconhecimento dessa relação hierárquica deriva de diferentes fontes. Segundo Weber, nas organizações burocráticas, essa legitimação seria, a princípio, originária do cargo ou da função que cada um nelas ocupa. Segundo Arendt, quando a coerção ou a persuasão são utilizadas, inexiste a relação de autoridade; portanto, não há uma situação de legitimação da mesma.

Nas organizações escolares em geral, o que se observa freqüentemente é a legitimação da autoridade baseada no cargo ocupado. No caso do professor, tem sido o diploma do qual ele é portador que o habilita a estar no papel de detentor de um saber; no caso da direção da escola, a autoridade é legitimada também pelo cargo e pela responsabilidade legal que o acompanha. Na prática, no entanto, observa-se que há, e cada vez mais, uma resistência ao reconhecimento dessa autoridade, tanto por parte dos alunos em relação aos professores, quanto por parte dos professores em relação à direção.

Dentre as diferentes razões que explicam tal resistência, encontra-se a postura assumida por esses profissionais no interior da organização escolar.

O uso da coerção como fonte de aceitação da autoridade se dá quando nenhuma outra forma de legitimação é possível; é um sintoma da resistência do grupo em aceitar as regras e princípios previamente estabelecidos. A participação nesse contexto restringe-se ao cumprimento do formal, gerando um clima de revolta ou de apatia, que se reflete no comportamento dos alunos.

Os órgãos que teriam a tarefa de incrementar a participação, tais como associações de pais e mestres e conselhos de escola, que prevêem a participação de professores, pais, alunos e funcionários, não cumprem essa função, tornando-se meramente órgãos de legitimação do poder centralizado e de decisões previamente tomadas.

A atuação da direção da escola nesse sentido é fundamental na medida em que, como afirma Silva Jr. (1993), a tarefa do administrador escolar não é controlar o trabalho pedagógico, mas assegurar a existência de condições para que o ensino se realize. A legitimação da autoridade, dessa forma, seria baseada no reconhecimento do poder de articulação e da criação de elementos facilitadores da participação na escola, o que contribuiria para o estabelecimento de estruturas menos hierárquicas.

Quando a legitimação da autoridade se dá meramente pelo cargo burocrático ocupado, normalmente ocorre uma centralização das decisões formais nas mãos da 
direção e um individualismo exacerbado nas práticas ocorridas na sala de aula, que são compartilhadas pelo grupo como um todo, por receio de represálias. Nos grupos em que há o predomínio desse tipo de cultura, observa-se um baixo envolvimento dos profissionais entre si e com a escola, sendo muito freqüente a alta rotatividade de profissionais e a proliferação daqueles que dizem que nada há para ser feito.

Esse tipo de cultura gera uma atuação individualizada de cada professor em sala de aula, ocasionando, muitas vezes, uma ausência de referencial para o aluno e problemas sérios de indisciplina e baixo aproveitamento das atividades desenvolvidas.

Quanto ao reconhecimento da autoridade do professor pelo aluno, Luna e Davis colocam que, além da legitimidade conferida pelo conhecimento do qual o primeiro é detentor, é de fundamental importância o "compromisso genuíno com o processo pedagógico, ou seja, com a construção de sujeitos que, conhecendo a realidade, disponhamse a modificá-la em consonância com um projeto comum" (| 99| , p. 69).

A elaboração de um projeto comum, encontra-se na possibilidade real de participação dos diferentes atores do processo pedagógico nos destinos da escola .

Assim, é "preciso levar em conta a dimensão em que o modo de pensar e agir das pessoas que aí atuam facilita/incentiva ou dificulta/impede a participação dos usuários" (Paro, 1995, p.304). Isto é, além das regras e regulamentos, é necessário pensar sobre a cultura de relações estabelecida na escola e em que medida as concepções de autoridade e hierarquia que estão sendo compartilhadas se refletem na possibilidade real de participação.

\section{REFERÊNCIAS BIBLIOGRÁFICAS}

ARENDT, H. Entre o passado e o futuro. 2. ed. São Paulo: Perspectiva, 1972.

BALL, S. The Micro-politics of the school. London: Methuen, 1987.

BATES, R. J. Corporate culture, schooling and educational administration. Educational Administration Quartely. v. 23, n.4, p. 79-1 I5, Fall, 1987.

BRUNET, L. Clima de trabalho e eficácia da escola. In: NÓVOA, A. As Organizações escolares em análise. Lisboa: Dom Quixote, 1995, p. 121 -40.

CARVALHO, L. M. Clima de escola e estabilidade de professores. Lisboa: EDUCA, 1992.

CROZIER, M. Le Phénomene bureaucratique. Paris: Seuil, 1963.

ELMORE, R. F. Reform and the culture of authority in schools. Educational Administration Quartely.v. 23, n. 4, p. 60-78, nov. 1987. 
ERICKSON, F. Conceptions of school culture: na overview. Educational Administration Quartely, v. 23, n. 4, Fall, 1987.

GEERTZ, C. The Interpretation of cultures. New York: New York Basic Books Inc. Publishers, 1973.

GOMES, R. Cultura de escola e identidade dos professores. Lisboa: Educa, 1993.

HOFSTEDE, G. et al. Measuring organizational cultures: a qualitative and quantitative study across twenty cases. Administrative Science Quarterly, v. 35, 1990.

LÉVI-STRAUSS. Antropologie structurale. Paris: Poln, 1958.

LIEBERMAN, A. Schools as collaborative cultures create the future now. Lewes: The Falmer Press, 1990.

LIMA, L. A Escola como organização e a participação na organização escolar. Braga: Instituto de Educação, Universidade do Minho, 1992.

LUNA, S., DAVIS, C. A Questão da autoridade na educação. Cadernos de Pesquisa. n. 76, p. 65-70, fev. 1991.

MORGAN, G. Imagens da organização. Rio de Janeiro: Civilização Brasileira, 1995.

MOSCOVICl, S. A Representação social da psicanálise. Rio de Janeiro: Zahar, 1978.

MOTTA, F. C. P. Cultura nacional e cultura organizacional. In: VASCONCELOS, J. et al. Recursos humanos e subjetividade. Rio de Janeiro: Vozes, 1996. p. 197-229.

NÓvOA, A. As organizações escolares em análise. Lisboa: Dom Quixote, 1995.

PARO, V. Por Dentro da escola pública. São Paulo: Xamã, 1995.

SILVA JR., C. A. A Escola pública como local de trabalho. São Paulo: Cortez, 1993.

THÉVENET, M. A Cultura de empresa hoje em dia. Revista de Administração, v. 26, n. 2, p. 32-9, abr./jun. 1991.

THOMPSON, V. Moderna organização. Rio de Janeiro: MECNSAID, 1967.

WEBER, M. Economia y sociedad. México: Fondo de Cultura Economica, 1944.

WISE, A. Legislated learning. the bureaucratization of the american classroom. Berkeley: University of California Press, 1982. 